\title{
Arındırılmış Ekonomik Katma Değer (REVA) Yöntemiyle Performans Ölçümü: Turizm Sektörü Uygulaması
}

\author{
Ulaş ÜNL $\ddot{U}^{*}$ \\ Oğuz SAYGIN**
}

\section{$\ddot{O Z E T}$}

Muhasebe temelli geleneksel performans ölçüm yöntemlerinin yetersizliği üzerine sermaye piyasalarında firma değerlemek için değer temelli performans ölçüm yöntemleri geliştirilmiştir. Bu noktadan hareketle bu çalışmanın temel amacı, Türkiye'de yeni bir yöntem olup daha önce uygulanmamış olan Arındırılmış Ekonomik Katma Değer (REVA) yöntemini 2012 yılında Borsa İstanbul'da işlem gören turizm sektörü firmalarına uygulamaktır. Çalışmanın sonucuna göre turizm sektörü firmalarının 2012 yılı için genel olarak değerlendirildiğinde hissedar değeri yaratamadıklarl ve değer yaratmak yerine mevcut sermayelerini tükettikleri tespit edilmiştir.

Anahtar Kelimeler: Arındırılmış Ekonomik Katma Değer (REVA), Piyasa Katma Değeri (MVA), Finansal Performans Ölçüm Yöntemleri, Turizm Sektörü.

JEL Sinıflandirmast: L25, G30.

Performance Measurement with the method of Refined Economic Value Added (REVA): Evidence from Tourism Industry

\section{ABSTRACT}

The accounting-based traditional performance measures have been regarded as inadequate and value-based contemporary performance measures have been tried to be developed. In this respect, the main aim of this study, Refined Economic Value Added (REVA) which is a new method for Turkey is to evaluate on the tourisn sector companies traded on Istanbul Stock Exchange for the year of 2012. The REVA of the tourism companies listing in Istanbul Stock Index have been calculated by using the financial statements belong to 2012 period. According to the findings, evaluate on the tourism sector companies traded on Istanbul Stock Exchange for the year of 2012. The result of this study, tourism sector companies have not been failed to obtain shareholder value the year of 2012 and They have spent available capital instead of creating value.

Keywords: Refined Economic Value Added (REVA), Market Value Added (MVA), Financial Performance Measures, Hospitality Industry.

Jel Classification: L25, G30.

\footnotetext{
* Yrd. Doç. Dr. Ulaş Ünlü, Nevşehir Hacı Bektaş Veli Üniversitesi MYO/Finansman, ulasunlu@gmail.com

** Öğr.Gör. Oğuz Saygın, Nevşehir Hacı Bektaş Veli Üniversitesi MYO/Finansman, osaygin@nevsehir.edu.tr
} 


\section{GíRiş}

Son yıllarda yaşanan küreselleşme süreciyle birlikte işletmeler son derece zor bir rekabetle karşı karşıya kalmışlardır. Rekabet koşullarının artması işletmelerin performans ölçümünde geleneksel performans ölçüm yöntemlerinin yetersiz kalmasına neden olmuştur. Bununla birlikte işletmelerin temel amacı olan kar maksimizasyonu yerini hissedar değeri maksimizasyonuna bırakmıştır.

Firma amacının hissedar değerinin maksimum kılınması olarak tanımlanması finansal performansın ölçümünde "değer" kavramını ön plana çıkarmaktadır. Finansal varlıkların gerçek değerinin belirlenmesi oldukça önemlidir. Bununla birlikte değeri belirlenen varlıkların etkin ve verimli yönetilmesi sürecinde, değer yaratan unsurların belirlenmesi, belirlenen unsurların doğru analiz edilmesi ve varlığın gerçek değerinin belirlenmesi arasında içsel bir ilişki bulunmaktadır (Ercan vd. 2006:1 ).

Değere dayalı yönetim, işletme içerisinde alınacak tüm kararların değer yaratmaya yönelik olmasını amaç edinen bir yönetim anlayışı olarak tanımlanmaktadır. Söz konusu yaklaşım, yöneticileri ve çalşanları hissedarlar gibi düşünmeye ve hareket etmeye cesaretlendirmekte, geleneksel yönetim davranış ve alışkanlıklarını değiştirip, işletme içerisinde değer kavramını ön plana çıkartarak, onları bu hedefe yönlendirmektedir (Ercan ve Ban, 2005: 334).

Hissedarlar açısından değer oluşturulması ancak, yatırımların getirisinin maliyetinden yüksek olması durumunda olasıdır. Böylece son yıllarda, hissedar değeri yaratma kavramı, sayıları gittikçe artan, alanında önemli şirketlerin üst düzey yöneticisi için ulvi bir amaç haline gelmiştir. Günümüzde hem teorik hem de pratik olarak hissedar değerini maksimum kılan stratejileri seçmek, her yönetici için neredeyse kaçınılmaz bir durum haline gelmiştir (Sakarya, 2008: 176-177).

Değer yaratmanın ve ölçmenin temel unsurları şu şekilde sıralanabilir (Chambers, 2009: 24);

- Gerçek piyasada, yatırılan sermayenin getirisi yatırılan sermayenin firsat maliyetinden yüksek olursa değer yaratıldığı anlamına gelir.

- Sermayenin getirisi sermaye maliyetinden ne kadar yüksek olursa o kadar fazla değer yaratılmış olur.

- Beklenen nakit akımlarının bugünkü değerini veya ekonomik karı maksimize edecek stratejiler seçilmelidir.

- Bir firmanın hisse senedinin borsa değeri, piyasada o firmanın gelecekteki performansına ilişkin beklentilere dayalı olarak oluşan gerçek değere eşittir.

- Hisse senedi sahiplerinin getirileri, firmanın gerçek performansından önce beklentilerdeki değişimlere bağlidır.

Literatürde yaratılan değeri ölçmeye yönelik birçok çağdaş finansal performans ölçütü bulunmaktadır. Bunlar arasında; Ekonomik Katma Değer (EVA), Arındırılmış Ekonomik 
Katma Değer (REVA), Piyasa Katma Değeri (MVA), Hissedar Katma Değeri (SVA), Yatırımın Nakit Akım Karlılı̆gı (CFROİ), Nakit Katma Değer (CVA) sayılabilir. Bu çalışmada turizm sektörü firmalarının finansal performans ölçümünde, Ekonomik Katma Değerin bir takım eksikliklerini giderdiği öne sürülen Arındırılmış Ekonomik Katma Değer yöntemi ölçüt olarak kullanılacaktır.

Türk turizm sektörünün varolan durumu değerlendirildiğinde, sektörde yer alan firmaların hissedar değeri yaratıp yaratmadıkları ve yaratılan değerin doğru bir şekilde tespit edilmesinin, turizm sektörü açısından oldukça önemli olduğu düşünülmektedir. Aşağıda dünya ve Türk turizm sektörüyle ilgili genel bir değerlendirme yapılmıştır.

Turizm sektörü, ulusal ekonomiye katkısı bağlamında döviz girişini artırıcı ve istihdam yaratıcı faydalarının yanında emek yoğun bir sektör olması sebebiyle geniş bir istihdam alanı da yaratmaktadır. Toplulukların bulundukları ülkeden farklı ülkelere gerçekleştirdikleri ziyaretler neticesinde, küresel boyutta, kültürel ve toplumsal iletişimin güçlendirilmesini ve gelişimini sağlayarak dünya barışının korunmasında önemli düzeyde payı bulunan bir sektördür. Ülkemizde olduğu gibi dünya ülkelerinde de turizm, üzerinde önemle durulan ve planlaması yapılarak cari açık, enflasyon ve işsizlik gibi sorunların çözümünde çıkış yolu olarak göz önünde bulundurulan bir sektördür. Dünya ölçeğinde 2011 yılında, turizm sektörü GSMH'ye doğrudan 2 trilyon \$'lık katkı yaratmış olup, bu rakam dikkate alındığında küresel GSYH'ye katkısı otomotiv- sanayi katkısından iki kat fazla, küresel kimya endüstrisinin katkısının ise üçte birinden fazladır. Bu durum turizm sektörünün küresel ölçekte ekonomiye katkısının önemli boyutlarda olduğunu göstermektedir. Küresel çapta 255 milyonu aşkın kişiye istihdam sağlayan (küresel istihdamın \% 8,7'sı) turizm sektörü, dünyadaki en büyük sektörlerden biridir ve küresel ekonomik gelişime güçlü bir ivme kazandırmaktadır (Travel \& Tourism Economic Impact, WTTC, 2012).

Türkiye misafirperverlik geleneği, 1lıman iklimi, çekici ve uzun kıyı şeridinin yanında, doğal güzellikleri, eşsiz tarihi mekânları, arkeolojik ören yerleri ve giderek gelişen altyapısıyla turizm sektörünün oldukça gelişmiş olduğu bir ülkedir. Turizm sektörü bu etkenlere bağlı olarak son dönemlerdeki ekonomik kalkınmanın arkasındaki en önemli itici güçlerden biri olmuştur. (T.C. Başbakanlık Yatırım Destek ve Tanıtım Ajansı, Türkiye Turizm Sektörü Raporu, 2010). Ülkemizde yaklaşık 2 milyon kişiye istihdam sağlayan sektör, 2011 y1lında 86 milyar \$ değerinde ekonomik faaliyette bulunmuştur. Bu rakam Türkiye'nin toplam GSMH'sinin yaklaşık \% 10,9'una denk gelmektedir. Diğer taraftan, 2011 yılında ülkemize gelen turist yaklaşı 34 milyon civarında olup, elde edilen turizm geliri 23 milyar \$'dır (The Travel \& Tourism Competitiveness Report, World Economic Forum, 2013).

Dünya ekonomik forumu tarafindan yayımlanan 2013 seyahat ve turizm rekabet gücü raporuna göre, rekabet gücü indeks siralamasında 2011 yılında 50. Sirada yer alırken 2013 yılında 4 sıra ilerleyerek 46. Sırada yer almıştır. Türkiye'nin zengin kültürel kaynakları (Dünya sıralamasında 19.), 20 tane Dünya Kültür Mirasına girmiş mekânları, çok sayıda uluslararası fuar ve sergiler gerçekleştirmesi ve güçlü yaratıcı endüstrilere sahip olması turizm 
yönünden güçlü olduğu unsurlardır. Ayrıca, 2011 yılı turizm sektör raporundan bugüne turizm sektörüne ilişkin politika kuralları ve düzenlemeler, sektörü destekleyici ve sektörün gelişmesine dönük düzenlemelerdir. Bunlara ek olarak, dünya sıralaması olarak havayolu altyapıs1 alanında 29. Sirada, turizm altyapısı alanında 45. Sirada bulunması bu alanlarda sektörün ilerleme kaydettiğinin bir göstergesidir. Ancak, güven ve emniyet konularında iyileştirmeler olmasına rağmen endişe verici bir ülke olduğu ve bazı alanlarda hala dünya genelinde geride kaldığı gözlenmiştir (The Travel \& Tourism Competitiveness Report, World Economic Forum, 2013).

\section{EKONOMIKK KATMA DEĞER (EVA), PIYASA KATMA DEĞERİ (MVA) VE ARINDIRILMIŞ EKONOMIK KATMA DEĞER YÖNTEMİ (REVA)}

Son yıllarda rekabet koşullarında meydana gelen köklü değişimler işletmelerin finansal performanslarının bu değişimler neticesinde hangi ölçütler kullanılarak ölçüleceğ $i$ konusunu gündeme getirmiş̧ir. Bununla birlikte geleneksel performans ölçütlerinin yerine bir takım yeni ölçütler geliştirilmiştir. Bunların içerisinde şüphesiz en önemli ölçütlerden birisi de Ekonomik Katma Değerdir (EVA).

EVA kavramı yeni bir yöntem olmayıp muhasebedeki "artık gelir" kavramına gelir ve sermaye üzerinde bir takım uyarlamalar yapılarak geliştirilmiştir. EVA artık gelir kavramından çok fazla bir fark göstermemesine karsin pek çok firma tarafindan benimsenmiştir (Öztürk, 2004: 351-368). EVA, değer bazlı yönetim anlayışından yola çıkarak firmaya uzun dönemde katma değer yaratacak tüm politikaları bünyesinde bulunduran bir disiplin olarak Stern Stewart Danışmanlık firması tarafından 1980'li yılların sonlarında ortaya atılmış bir kavramdır (İşeri, 2003: 77).

EVA'nın temel amacı indirgenmiş nakit akımları değerlemesiyle uyumlu ve cari piyasa değeriyle yüksek korelasyona sahip olan dönemsel performansın ölçüm yönteminin yaratılmasıdır. EVA hem borcun maliyetini hem de AOSM'yi hesaba kattığı için muhasebe karından ayrılmaktadır. Serbest nakit akımları ile işletmenin cari piyasa değeri arasında oldukça düşük bir ilişki söz konusudur, zaten yatırımların gelecekteki faydalarını göz önüne almamaktadır. EVA ise yatırımların gelecekteki harcama ve faydalarını da göz önüne aldığından dolayı serbest nakit akımlarına göre cari piyasa değeri ile daha yüksek bir korelasyona sahiptir (Gürbüz ve Ergincan, 2004: 249).

EVA'nın hesaplanması için literatürde değişik yaklaşımlar bulunmakla beraber en yaygın olarak aşağıdaki şekilde hesaplandığı gözlenmiştir (Damodaran, 2002: 864);

$\mathrm{EVA}=(\mathrm{YSG}-\mathrm{AOSM}) \times \mathrm{YS}$

Burada; YSG, yatırılan sermayenin getirisini, AOSM, ağırlıklı ortalama sermaye maliyetini, YS ise yatırılan sermayeyi ifade etmektedir.

Hesaplama sonucu EVA pozitif bir değer bulunmuş ise işletmenin katma değer yarattığı, diğer bir anlamda da firmanın ortaklarına hissedar değeri yarattığı söylenebilir. 
Diğer taraftan EVA negatif bir değer hesaplanmışsa da işletme sermayesinin değer tükettiği, erozyona uğrattığı sonucu ortaya çıkmaktadır.

Akademik literatür incelendiğinde EVA için birçok eleştiri bulunduğu gözlenmektedir. EVA'nın kullanımına yapılan en önemli eleştirilerden biri, işletmelerin finansal tablolarında raporlanan sonuçlarda yapılması gereken zorunlu düzeltmelerdir. Buna bağlı olarak EVA'nın muhasebe temelli geleneksel performans ölçütlerine göre gerçekçi bir ölçüt olmasına rağmen, temelde muhasebe verilerinden yararlandığı için bu ölçütlerde karşılaşılan bazı kısıtlamalardan dolayı geçerliliği zedelenmektedir. Ancak EVA savunucuları, EVA hesaplanırken yapılan bazı düzeltmeler ile muhasebe verilerinin gerçek ekonomik performansa dönüştügünü savunmaktadırlar. Ayrıca EVA hesaplamalarında, cari yıla ait vergiden sonraki net faaliyet kârı, yatırılan sermaye miktarı ve sermaye maliyeti gibi tarihi verilere dayalı finansal ölçütler üzerinde fazla durulması, EVA'nın işletmenin gelecekte göstermesi beklenen performansı yansıtmasında sıkıntılar doğurabileceği öne sürülmektedir. Dolayısıyla hesaplamaların geleceğe dönük beklenen performansı yansıtmaktan uzak olacağı ifade edilmektedir. Değere dayalı yönetim anlayışını benimsemiş bir işletmenin ana amacının, gelecekte yaratılması beklenen EVA değerleri toplamının net bugünkü değerinin hissedarlar açısından maksimize edilmesi olduğu düşünüldügünde, hesaplamalarda gelecekte değer yaratması beklenen unsurların dikkate alınmaması EVA için önemli bir dezavantaj oluşturmaktadır. (Bayrakdaroğlu, 2009:69-71).

Finansal açıdan bakıldığında ise, belirli bir döneme ait EVA'nın firmanın hissedarlarının ve yöneticilerinin gelecek yıllarda pozitif ekonomik katma değer yaratılmasına yönelik beklentilerini yansitmaktan uzak kalmakta olup, değer maksimizasyonu boyutunda, firmanın piyasa değerinin esas belirleyicisi gelecekte yaratılması beklenen EVA'ların net bugünkü değeridir. Bu durumu yansıtan ölçüt ise piyasa katma değeri (MVA)'dir (Alp, Demirgüneş, Ban ve Öztürk, 2009: 60).

EVA, firmanın elde ettiği karın firmanın kullandığı sermayenin maliyetini ne ölçüde karşıladığını ölçen bir ölçütken, bu ölçütün tamamlayıcısı olan ve yaratılan katma değerin firmanın piyasa değerine nasıl yansıdığının bir göstergesinin ise MVA olduğu söylenebilir. Firmaların piyasa değeri ile defter değeri arasındaki farkın maksimum kılınması demek hissedarlar açısından servetlerinin değerinin maksimum kılınabilmesi anlamına gelmektedir. Aynı zamanda, MVA yöntemi hissedarların servetlerindeki artışı ölçmesiyle beraber firma kaynaklarının ne ölçüde etkin ve verimli olarak değerlendirildiğini de ortaya koymaktadır. Bu yöntemle, firmanın yatırımcılardan sağladığı nakit girişi ve yatırımcıların paylarını bugünkü fiyattan elden çıkarması sebebiyle doğan nakit çıkışı arasındaki farkın ölçüsüdür MVA' yı şu şekilde hesaplamak mümkündür (Stewart, 1991);

MVA= Piyasa Değeri - Yatırılan Sermaye 
EVA'nın dezavantajlarını gidermek amacıyla REVA yöntemi geliştirilmiştir. REVA yöntemi EVA yönteminin tamamlayıcısı olarak birlikte kullanılabildiği gibi, performans ölçütünü kullanacak işletmenin ölçeğine göre ikisinden biri de seçilebilmektedir. En uygun performans ölçütü, yönetim stratejisinin hissedar değerini nasıl etkilediğini riske göre düzeltilmiş yatırılan sermayenin getirisi olarak ölçen performans ölçütüdür. Bu bağlamda REVA yönteminin üstünlüğü, EVA yöntemi piyasa tabanlı sermaye ölçütünü varlıkların defter değerini dikkate alarak uygulamaktayken; REVA yöntemi hissedar değerini ölçmekte, piyasa tabanlı sermaye ölçütünü varlıkların defter değerini değil piyasa değerini dikkate alarak uygulamasından gelmektedir. REVA ise şu şekilde formüle edilebilir (Bacidore vd., 1997; Lee ve Kim, 2009);

\section{REVA = VSNFK- (Piyasa Değeri $x$ AOSM)}

Burada; VSNFK, vergi sonrası net faaliyet karını, AOSM ise ağırlıklı ortalama sermaye maliyetini ifade etmektedir. Hesaplama sonucu EVA'ya benzer şekilde eğer pozitif bir değer bulunmuş ise işletmenin hissedar değeri yarattığı ifade edilebilir. REVA'nın hesaplanışıly ilgili ayrıntılı bilgi yöntem kısmında verilecektir.

\section{LITERATÜR TARAMASI}

Ekonomik Katma Değer yöntemine alternatif olarak, Bacidore vd., (1997) Arındırılmış Ekonomik Katma Değer yöntemini geliştirmişlerdir. Bacidore vd. (1997), çalışmalarında 1988-1992 döneminde turizm sektörü firmaları için EVA ve kendi geliştirdikleri REVA ölçütlerini karşılaştırmışlardır. Çalışmanın sonucunda finansal performans ölçütü olarak REVA'nın EVA'ya göre daha iyi bir ölçüt olduğu savunulmaktadır. Bunun nedeni olarak da çalışmada, işletmenin gerçek anlamda hissedar değeri elde edebilmek için sermaye maliyetiyle piyasa değerinin çarpılmasının daha doğru olacağı gösterilmiştir. Bilindiği gibi EVA'da yatırılan sermaye hesaplanırken varlıkların defter değerleri kullanılmaktadır. Lee and Kim (2009) çalı̧̧masında 1985-2004 örneklem dönemi için, Ekonomik Katma Değer, Arındırılmış Ekonomik Katma Değer, Piyasa Katma Değeri, Faaliyet Nakit Akımı, Aktif Karlılığ1 ve Özkaynak Karlılığını karşıllaştırmışıı. Araştırmanın sonucuna göre turizm firmaları için REVA ve MVA'nın performans değerleme yöntemleri olarak anlamlı sonuçlar verdiği tespit edilmiştir.

Türkiye'de yapılan çalışmalar incelendiğinde REVA ile ilgili bir çalışmanın olmadığı gözlenmiştir. Çalışmalar genellikle EVA ile ilgili olup şu şekilde özetlenebilir. Şamiloğlu (2004) çalş̧masında 1995-2002 döneminde imalat firmaları için, EVA ile artık gelir ve muhasebe karlarını karşılaştırmıştır. Çalışmanın sonucunda BISST'de işlem gören imalat sanayi firmalarının hisse başına getirilerinin varyansının \%7.9'u EVA tarafindan açıklandığı bulunmuştur. Gürbüz ve Ergincan (2004) yaptıkları çalışmada 1995-2000 inceleme döneminde firmaların ekonomik katma değerlerinin arttığı ancak bu artışı piyasa değerlerine tam anlamıyla yansıtamadıklarını ortaya koymuşlardır. Kara (2005) çalışmasında piyasa değeri, MVA ve EVA ile geleneksel performans ölçütlerini istatistiksel olarak karşılaş̧ırmıştır. Sonuç olarak geleneksel performans ölçütlerinin bir firmanın piyasa 
değerindeki değişimi açıklayamadığını tespit etmiştir. Bayrakdaroğlu ve Ünlü (2009) ise çalışmalarında BİST ile NYSE borsalarını EVA ve MVA performans ölçütleri açısından karşılaştırmışlardır. Analiz sonuçlarına göre Borsa İstanbul hissedar değeri yaratma konusunda başarılı olamamış ayrıca değer yaratmak yerine mevcut sermayeyi tüketmiştir. NYSE ise olumlu bir performans göstermiş ve hissedarlara katma değer yaratmıştır. Akyüz (2013), çalışmasında EVA ve MVA yöntemlerini seramik işletmeleri için hesaplamıştır. EVA sonuçlarına göre firmaların tüm dönemlerde ekonomik katma değer yaratamadığı, ekonomik katma değer kaybına uğradıkları ve negatif EVA değerleri elde ettiğini tespit edilmiştir. MVA sonuçları da EVA sonuçlarına benzer olup firmalar negatif MVA değerleri elde etmişlerdir. Yılmaz ve Bastı (2013) çalışmalarında imalat sanayi firmalarının performanslarını EVA ve MVA yöntemlerine göre hesaplamışlardır. Analiz sonuçlarına göre, EVA ortalaması en yüksek olan grubun büyük işletmeler, MVA ortalaması en yüksek olan grubun ise küçük işletmeler olduğu tespit edilmiştir. Çalışmada ulaşılan başka bir sonuç da, EVA'nın MVA'yı açıklama gücünün oldukça zayıf çıkmasıdır.

\section{VERİ YAPISI VE YÖNTEM}

$\mathrm{Bu}$ çalışmanın temel amacı Borsa İstanbul'da faaliyet gösteren turizm sektörü firmalarının 2012 yılında Piyasa Katma Değeri ve Arındırılmış Ekonomik Katma Değerlerinin hesaplanarak hissedar değeri ve piyasa katma değeri yaratıp yaratmadıklarını ortaya koymaktır. Çalışma EVA'nın literatürde yer alan bir takım eksiklikleri ve eleştirileri göz önünde bulundurularak alternatif bir yöntem olması ve Türkiye'de henüz uygulama alanı bulamayan REVA'ya odaklanmıştır. EVA yöntemi, varlıkların defter değerini temel almaktayken, REVA yöntemi varlıkların piyasa değerini baz alarak firmanın hissedar değeri yaratıp yaratmadığını belirlemektedir. Çalışmada, REVA yönteminde piyasa değerinin hesaplamaya katılması nedeniyle, piyasa değerini dikkate alan diğer bir performans ölçüm yöntemi olan MVA da çalışma kapsamına alınmıştır. Her iki yöntemin de firmaların piyasa değerlerini dikkate alması, bu yöntemlerin sonuçlarının birbiriyle örtüşüp örtüşmediği sorusunu akla getirmektedir. Bu bağlamda, EVA yönteminin piyasa değerini dikkate almayarak, sadece defter değerini baz alması sebebiyle bu çalışma kapsamında hesaplamaya dahil edilmemiştir. Bu noktadan hareketle çalışma kapsamında turizm sektöründe faaliyet gösteren 10 firmanın REVA ve MVA değerleri birlikte hesaplanmış ve çıkan sonuçlar yorumlanmıştır.

$\mathrm{Bu}$ araştırmada Borsa İstanbul'a kote olmuş, 2012 y1lında faaliyet gösteren ve veri yap1s1 uygun 10 turizm firmas1 (AVTUR, AYCES, FVORİ, MAALT, MARTI, METUR, NTTUR, PKENT, TEKTU, UTPYA) kullanılmıştır.

Bilanço verileri bağımsız denetimden geçmiş 12 aylık veriler olup Kamuyu Aydınlatma Platformu resmi internet sitesinden ${ }^{1}$ temin edilmiştir. Borçlanma maliyetinin tespiti her bir firma için oldukça zor olduğundan ortak bir ölçüt olarak Türkiye Kalkınma

\footnotetext{
${ }^{1}$ www.kap.gov.tr
} 
Bankasının orta vadeli yatırım kredilerine uyguladığı yıllık faiz oranı ${ }^{2}$ baz alınmıştır (Yılgör, 2005). Özsermaye maliyeti ise CAPM'in standart formülü kullanılarak tespit edilmiştir ${ }^{3}$. Burada piyasanın getirisi $\left(\mathrm{R}_{\mathrm{m}}\right)$ olarak XTRZM (Turizm) endeksinin getirisi kullanılmış olup veriler Borsa İstanbul resmi internet sitesinden alınmışıtr ${ }^{4}$. Risksiz faiz oranı $\left(\mathrm{R}_{\mathrm{f}}\right)$ olarak, gösterge niteliği taşıması ve işlem hacminin yoğun olması sebebiyle hazine bonosu yıllık bileşik referans faiz oranı aylık değerlere dönüştürülerek çalışmada kullanılmıştır. Risksiz faiz oranı verileri Türkiye Cumhuriyet Merkez Bankası resmi internet sitesinden sağlanmıştır . Özsermayenin ağırlığı için ise bilanço verilerinden yararlanılmıştır. Ayrıca piyasa değerleri hesaplanırken halka açıklık oranları dikkate alınmış olup dolaşımda bulunan hisse senedi sayısı verileri için bağımsız denetim raporları kullanılmıştır. Gerekli veriler Kamuyu Aydınlatma Platformundan temin edilmiştir.

MVA şu şekilde hesaplanmıştır;

MVA= Piyasa Değeri - Yatııılan Sermaye

Firmaların piyasa değerleri halka açıklık oranları dikkate alınarak (dolaşımda bulunan hisse senedi sayısı $\mathrm{x}$ hisse senedinin kapanış fiyatı) hesaplanmıştır. Yatırılan sermayeyi hesaplamak için ise toplam varlıklardan faiz yükümlülüğü gerektirmeyen borçlar çıkarılmış ve yatırılan sermayenin defter değerine ulaşılmıştır. Yatırılan sermayenin defter değerine ise LIFO rezervleri, şüpheli ticari alacak karşıllığındaki artış ve aktifleştirilen harcamalar (Ar-Ge gibi) nakit esasıyla ve bilanço dışı kalemlerle ilgili düzeltmeler eklenmiş "Yattrılan Sermaye" rakamına ulaşılmıştır (Bacidore vd., 1997).

REVA'yı ise şu şekilde hesaplamak mümkündür;

REVA= VSNFK- (Piyasa Değeri x AOSM)

Burada; VSNFK, vergi sonrası net faaliyet karını, AOSM ise ağırlıklı ortalama sermaye maliyetini ifade etmektedir.

VSNFK ulaşmak için birtakım düzenlemeler yapmak gerekmektedir. Vergi sonrası net kara, ertelenen vergilerdeki artış, LIFO rezervlerindeki artış, şerefiye amortismanı artışı, şüpheli ticari alacak karşıllğındaki artış ve aktifleştirilmiş Ar-Ge giderlerindeki artış eklenerek "Düzeltilmiş vergi sonrası net kar" rakamına ulaşı1ır. Vergi sonrası faiz giderini hesaplamak için, "faiz giderine" varsa "finansal kiralama faiz gideri" eklenerek "düzeltilmiş faiz giderine" ulaşılır. Bu rakamdan da faiz gideri ile ilgili vergi avantajı (Türkiye'de \%20 kurumlar vergisi) düşülerek "vergi sonrası faiz gideri" bulunur. Düzeltilmiş vergi sonrası net kar ile vergi sonrası faiz gideri toplanıp, "Vergi sonrası net faaliyet karına" ulaşmak mümkündür (Bacidore vd., 1997).

Özetlemek gerekirse;

\footnotetext{
${ }^{2}$ www.dpt.gov.tr

${ }^{3} \mathrm{~K}_{\mathrm{e}}=\mathrm{R}_{\mathrm{f}}+\beta\left(\mathrm{R}_{\mathrm{m}}-\mathrm{R}_{\mathrm{f}}\right)$

${ }^{4}$ borsaistanbul.com

${ }^{5}$ www.tcmb.gov.tr
} 
VSNFK = Düzeltilmiş vergi sonrası net kar + Vergi sonrası faiz gideri

şeklinde hesaplanır. Firmaların piyasa değerleri ise halka açık hisse senedi sayısı ile hisse senedi fiyatının çarpılması sonucu elde edilmiştir. Turizm sektörü firmalarının AOSM değerleri ise CAPM'in standart formülüyle $\left[K_{e}=R_{f}+\beta\left(R_{m}-R_{f}\right)\right]$ hesaplanmıştır.

\section{BULGULAR}

Firmaların Vergi Sonrası Net Faaliyet Karı ve Yatırılan Sermaye değerleri Tablo 1'de verilmiştir.

Tablo 1: Turizm Firmalarının VSNFK ve Yatırılan Sermaye Değerleri (TL)

\begin{tabular}{|l|r|r|r|r|}
\hline Firmalar & \multicolumn{1}{|l|}{$\begin{array}{l}\text { Düzeltilmiş } \\
\text { Vergi } \\
\text { Sonrası Net } \\
\text { Kar (A) }\end{array}$} & $\begin{array}{l}\text { Vergi Sonrası } \\
\text { Faiz Gideri (B) }\end{array}$ & $\begin{array}{l}\text { Vergi Sonrası } \\
\text { Net Faaliyet } \\
\text { Karı(VSNFK) } \\
\text { (A+ B) }\end{array}$ & $\begin{array}{l}\text { Yatırılan } \\
\text { Sermaye }\end{array}$ \\
\hline AVTUR & -2.035 .939 & 769.322 & -1.266 .617 & 67.708 .033 \\
\hline AYCES & 2.307 .630 & 534.581 & 2.842 .211 & 105.916 .197 \\
\hline FVORI & 803.307 & 28.730 & 832.037 & 127.432 .376 \\
\hline MAALT & 3.307 .216 & 596.367 & 3.903 .583 & 55.473 .516 \\
\hline MARTI & -12.844 .475 & 20.561 .396 & 7.716 .921 & 352.109 .952 \\
\hline METUR & 6.691 .161 & 1.305 .150 & 7.996 .311 & 16.287 .575 \\
\hline NTTUR & 32.595 .639 & 29.284 .958 & 61.880 .597 & 637.989 .842 \\
\hline PKENT & -3.060 .786 & 3.475 .201 & 414.415 & 32.445 .504 \\
\hline TEKTU & 1.964 .270 & 664.710 & 2.628 .980 & 181.403 .058 \\
\hline UTPYA & 6.164 .968 & 5.242 .574 & 11.407 .542 & 174.419 .597 \\
\hline
\end{tabular}

Tablodan da anlaşılacağı üzere yapılan düzeltmeler sonrasında VSNFK açısından turizm sektöründe faaliyet gösteren 10 firmadan sadece AVTUR'un vergi sonrası net faaliyet zararı söz konusudur. Ayrıca, MARTI ve PKENT firmalarının düzeltilmiş vergi sonrası net kar (A) rakamları negatiftir. Yapılan vergi sonrası faiz gideri (B) düzeltmesi yani finans alanında önemli bir husus olan faizin vergi tasarrufu etkisi ve finansal kiralama faiz giderlerinin hesaba katılması durumunda incelenen firmaların düzeltme sonrasında net faaliyet karına geçtikleri gözlemlenmiştir. Diğer taraftan, NTTUR firmasının sektöre kıyasla dikkat çekici düzeyde karlılığı olmasının nedeni firmanın esas faaliyet dışı finansal gelirleri arasında Net Holding A.Ş. hisse senetlerinin bilanço tarihinde borsada oluşan kapanış fiyatı üzerinden değerlenmesi yoluyla elde ettiği değer artış kazancından kaynaklanmaktadır. Bunun dışında ertelenen vergilerdeki artış düzeltmesinin, incelenen firmalar arasında en fazla bu firmaya etkisi olduğu tespit edilmiştir. 
Turizm firmalarının hesaplanan REVA ve MVA verileri Tablo 2'de sunulmuştur.

Tablo 2: Turizm Firmalarının REVA ve MVA Değerleri (TL)

\begin{tabular}{|l|r|r|r|r|r|}
\hline Firmalar & \multicolumn{1}{|l|}{ VSNFK } & \multicolumn{1}{l|}{ Piyasa Değeri } & \multicolumn{1}{l|}{ OSM } & \multicolumn{1}{l|}{ REVA } \\
\hline AVTUR & -1.266 .617 & 4.455 .000 & 0,0682 & -1.570 .868 & -63.253 .033 \\
\hline AYCES & 2.842 .211 & 973.278 .368 & 0,0776 & -72.731 .871 & 867.362 .171 \\
\hline FVORI & 832,036 & 1.537 .906 .134 & 0,1379 & -211.318 .112 & 1.410 .473 .758 \\
\hline MAALT & 3.903 .583 & 2.845 .183 .125 & 0,0709 & -197.883 .880 & 2.789 .709 .609 \\
\hline MARTI & 7.716 .921 & 41.509 .564 & 0,1298 & 2.326 .805 & -310.600 .387 \\
\hline METUR & 7.993 .481 & 7.817 .859 & 0,1420 & 6.883 .346 & -8.469 .716 \\
\hline NTTUR & 61.880 .597 & 83.706 .919 & 0,0928 & 54.112 .205 & -554.282 .922 \\
\hline PKENT & 414,415 & 8.484 .645 & 0,1099 & -518.679 & -23.960 .859 \\
\hline TEKTU & 2.628 .980 & 5.626 .186 .378 & 0,0689 & -385.027 .009 & 5.444 .783 .320 \\
\hline UTPYA & 11.407 .542 & 16.700 .000 & 0,1018 & 9.706 .856 & -157.719 .597 \\
\hline
\end{tabular}

Turizm sektörü firmalarının vergi sonrası net faaliyet karları incelendiğinde en yüksek değerin sirasıyla NTTUR, UTPYA, METUR ve MARTI'ya ait olduğu görülmektedir. Piyasa değeri açısından bakıldığında ise en yüksek piyasa değerine sırasıyla TEKTU, MAALT ve FVORİ sahiptir. Firmaların REVA değerleri incelendiğinde 10 firmadan 6 tanesinin negatif 4 tanesinin ise pozitif REVA değeri elde ettiği görülmektedir. Dolayısıyla inceleme döneminde 4 firmanın hissedarlarına katma değer yarattığı söylenebilir. En yüksek REVA değerini NTTUR elde etmişken, hissedarlarını en fazla kayba uğratan firma ise TEKTU olmuştur. Elde edilen MVA sonuçlarına göre ise sadece 3 firmanın piyasa katma değeri sağladığ 1 tespit edilmiştir. En yüksek piyasa katma değeri sağlayan firma TEKTU'dur.

Tablo incelendiğinde dikkat çeken en önemli bulgu REVA ve MVA sonuçlarının genel de birbiriyle çelişmesidir. Her iki yöntem de piyasa bazlı olmasına rağmen araştırma bulgularının farklılık göstermesi performans ölçütlerinin hesaplanmasından kaynaklanmaktadır. Daha açık bir ifadeyle sermaye maliyetinden daha fazla vergi sonrası net faaliyet karı elde etmiş bir firma pozitif REVA değerine ulaşırken, yatırılan sermayesinden daha fazla piyasa değerine sahip bir firma ise piyasa katma değeri yaratmaktadır.

\section{SONUÇ VE DEĞERLENDİRME}

Son yıllarda sermaye piyasalarında yaşanan gelişmelere paralel olarak firma performansının doğru bir şekilde ölçülmesi finans alanında oldukça önemli bir çalışma alanı olmuştur. Bununla birlikte yapılan çalışmalarda değer temelli farklı performans ölçütlerinin kullanıldığı göze çarpmaktadır. Fakat firmanın yaratmış olduğu değerin ölçümünde bu ölçütler birbiriyle çelişkili sonuçlar vermektedir. Bu noktada Türkiye'de "Arındırılmış Ekonomik Katma Değer” yöntemiyle ilgili çalışmanın yapılmamış olması bu çalışmanın 
temel çıkış noktasını oluşturmuştur. Çalışmanın bu yönüyle firmaların performans ölçümünde değere dayalı yönetim felsefesiyle yapılan ölçümlere katkıda bulunacağı düşünülmektedir.

Çalışmada elde edilen bulgulara göre turizm sektörü firmalarına bireysel anlamda bakıldığında 4 tanesinin hissedarlarına katma değer yarattığı görülmekle birlikte sektöre bütünüyle bakıldığında ortalamada hissedar değeri yaratılamadığı tespit edilmiş̧ir.

REVA performans ölçütü yatırımcıların sermaye piyasası odaklı değerlendirme yapma ihtiyaçlarını, ilgili yıldaki muhasebe verilerini kullanarak karşılamaktadır. Fakat REVA'nın hesaplanması oldukça karmaşık ve zordur. Türkiye'de piyasaların zayıf etkinlik düzeylerinde olması, volatilitesinin fazlalığı, derinliğinin azlığı, manipülasyona açıklığı gibi etkenler firmaların REVA değerlerinin sağlıklı değerlendirilmesini engelleyebilir. Bununla birlikte hisse senedi fiyatlarında meydana gelebilecek dönemsel değişimler REVA sonuçlarının gerçeği yansıtma gücünü sınırlandırabilir.

Son olarak Türkiye için henüz yeni bir performans ölçütü olan REVA hakkında daha sağlıklı değerlendirme yapabilmek için bu konuyla ilgili daha fazla araştırmaya ihtiyaç duyulduğu gerçektir. Bununla birlikte daha sonra yapılacak çalışmalarda hesaplamaların farklı sektörlerde daha fazla firmaya yapılması, yıl sayısının artırıarak REVA'nın hisse senedi getirilerini açıklama gücüne bakılması yararlı olabilir.

\section{KAYNAKLAR}

Akyüz, Yılmaz (2013), "Ekonomik Katma Değer (EVA) Ve Pazar Katma Değer (MVA) Analizi: İMKB'de İşlem Gören Seramik İşletmelerinde Bir Uygulama", Süleyman Demirel Üniversitesi İktisadi ve İdari Bilimler Fakültesi Dergisi, Cilt 18, Sayı 2, s. 339-356.

Alp, Ali.- Demirgüneş, Kartal.- Ban, Ünsal,- Öztürk, M. Başaran (2009), "Ekonomik Katma Değer Bakış Açısıyla Finanslama Kararları”, Celal Bayar Üniversitesi Sosyal Bilimler Enstitüsü Dergisi, Cilt 7, Sayı 2, s. 59-82.

Bacidore, Jeffrey M.- Boquist, John A..- Milbourn, Todd T.- Thakor, Anjan V. (1997), "The Search for the Best Financial Performance Measure”, Financial Analysts Journal, Vol. 53, No. 3, s. 11-20.

Bayrakdaroğlu, Ali (2009), "Hissedar Değeri ile Geleneksel ve Çağdaş Finansal Performans Ölçütleri Arasındaki ilişki: İMKB Şirketleri Üzerine Bir Uygulama”, Yayınlanmamış Doktora Tezi, Erciyes Üniversitesi, Sosyal Bilimler Enstitüsü, Kayseri.

Bayrakdaroğlu, Ali- Ünlü, Ulaş (2009), "Performans Değerlemede EVA ve MVA Ölçütleri: $\mathrm{Bu}$ Ölçütler Açısından İMKB ve NYSE’nin Karşılaştırılmalı Analizi”. Süleyman Demirel Üniversitesi İktisadi ve İdari Bilimler Fakültesi Dergisi, Cilt. 14, sayı 1, s. 287-312.

Chambers, Nurgül (2009), Firma Değerlemesi, Beta Yayınları, İstanbul.

Damodaran, Aswath (2002), Investment Valuation: Tool and Techniques for Determining The Value of Any Asset, second edition, John Wiley \& Sons Inc., New York. 
Ercan, M. Kamil,- Ban, Ünsal (2005), Finansal Yönetim, Gazi Kitabevi, Ankara.

Ercan, M. Kamil.- Öztürk, M. Başaran.- Küçükkaplan, İlhan.- Başçı, Eşref Savaş.Demirgüneş, Kartal (2006), Firma Değerlemesi ve Banka Uygulaması, Literatür Yayınları, İstanbul.

Gürbüz, A. Osman.- Ergincan, Yakup (2004), Şirket Değerlemesi: Klasik ve Modern Yaklaşımlar, Literatür Yayıncılık, Yayın No: 119, İstanbul.

İşeri, Müge (2003), “Ekonomik Katma Değer (Eva) Nedir? Ne Değildir?”, Banka-Mali Ve Ekonomik Yorumlar Dergisi, Y11 40, Say1 469, s. 75-83.

Kara, Hatice (2005), "Katma Değer Yaratmaya Dayalı Finansal Performans Ölçütü Olarak EVA (Economic Value Added) İMKB Şirketleri Üzerine Bir Uygulama,", SPK Yayınları, Yayın No 184, Ankara.

Lee, Seoki.- Kim, W. Gon (2009), "EVA, Refined EVA, MVA, or Traditional Performance Measures for the Hospitality Industry?" International Journal of Hospitality Management, Vol. 28, No. 3, p. 439-455.

Öztürk, M. Başaran (2004), "Finansal Performansın Ölçülmesinde Alternatif Bir Yöntem:

Ekonomik Katma Değer”, Atatürk Üniversitesi İktisadı ve İdari Bilimler Fakültesi Dergisi, Cilt 18, Say1 3-4, s. 351-368.

Sakarya, Şakir (2008), "Hissedar Değeri ve Hesaplanması Üzerine Bir Uygulama", Muhasebe-Finansman Dergisi, Sayı. 40, Ekim, s. 175-184.

Stewart III., Bennett, G (1991), The EVA Management Guide: The Quest for Value, Harper Business Publishers, 1991, New York.

Şamiloğlu, Famil (2004), "Faaliyet Kârı, Artık Gelir ve Ekonomik Katma Değer: Hangisi Hisse Senedi Getirileri İle Daha Yüksek İlişkilidir?”, İstanbul Üniversitesi İşletme Fakültesi Dergisi, Cilt 33, Sayı 1, s. 7-20.

T.C. Başbakanlık Yatırım Destek ve Tanıtım Ajansı (TYDTA) (2010), Türkiye Turizm Sektörü Raporu, Ankara.

The World Travel \& Tourism Council (WTTC) (2012), The Comparative Economic Impact of Travel \& Tourism, WTTC, London.

World Economic Forum (2013), The Travel \& Tourism Competitiveness Report, Switzerland.

Yılmaz, Tuncer.- Bast1, Eyüp (2013), İmalat Sanayi Şirketlerinin Ekonomik Katma Değer (EVA) Ve Piyasa Katma Değerine (MVA) Dayalı Performans Analizi: İMKB Örneği, Yönetim ve Ekonomi Araştırmaları Dergisi, Sayı 21, s. 82-105. 